\title{
Improving Mammography Screening Using Best Practices and Practice Enhancement Assistants: An Oklahoma Physicians Resource/Research Network (OKPRN) Study
}

\author{
Cheryl B. Aspy, PhD, Margaret Enright, MPH, LaWanna Halstead, RN, MPH, and \\ James W. Mold, MD, MPH
}

Purpose: In 2004 only $68 \%$ of women in 0klahoma over the age of 40 reported having a mammogram in the past 2 years, compared with $75 \%$ nationally. Strategies to improve mammography rates have been numerous but have generally included single strategies, such as physician education, practice audit and feedback, and reminders; flow sheets and results have been mixed. The purpose of this randomized controlled trial was to determine the impact of a practice facilitator and "best practice" interventions on mammography rates in a practice-based research network.

Methods: A total of 16 practices participated; 8 were assigned to intervention and 8 to usual care. Pre- and post-audits of mammography rates were conducted. Intervention practices received feedback with benchmarking, academic detailing, and the assistance of a practice enhancement assistant to help with practice redesign over a 9-month period.

Results: The groups differed significantly for both the proportion of mammograms offered to eligible patients $(P=.043)$ and for the proportion of patients with current mammograms $(P<.015)$. For the control group, 38\% of eligible women were offered a mammogram and $202(35 \%$ of those eligible) actually did have documentation that a mammogram had been performed. Fifty-three percent of the eligible patients in the intervention group were offered a mammogram and $52 \%$ of those eligible $(n=332)$ did have documentation in the chart that the mammogram had been completed.

Conclusion: The results suggest that these interventions can improve mammography rates in a range of practice settings. These findings are consistent with other studies that have tested multicomponent interventions. (J Am Board Fam Med 2008;21:326-333.)

The United State Preventive Services Task Force ${ }^{1}$ recommends screening mammography, with or without a clinical breast examination, every 1 to 2 years for women aged 40 and older based on reasonable evidence that it significantly reduces mortality from breast cancer. ${ }^{2-9}$ Although this evidence is strongest for women aged 50 to 69 , most studies

This article was externally peer reviewed.

Submitted 1 March 2007; revised 9 October 2007; accepted 12 October 2007.

From the Department of Family and Preventive Medicine, University of Oklahoma Health Sciences Center (CBA, JWM); and the Oklahoma Foundation for Medical Quality (ME, LH), Oklahoma City.

Funding: The analyses upon which this publication is based were performed under Contract Number 500-02-OK03, funded by the Centers for Medicare and Medicaid Services, an agency of the US Department of Health and Human Services. The content of this publication does not indicate a mortality benefit for women aged 40 to 49 and that the evidence is also generalizable for women older than 70 .

Mammography rates for Oklahoma women have lagged behind national rates. For example, in 1999 Oklahoma ranked 44th in the nation for women over 40 reporting ever having had a mammogram. ${ }^{10}$

necessarily reflect the views or policies of the Department of Health and Human Services, nor does mention of trade names, commercial products, or organizations imply endorsement by the U.S. Government. The authors assume full responsibility for the accuracy and completeness of the ideas presented. Publication number: 1D-040-MamarticleOK-0107.

Conflict of interest: none declared.

Corresponding author: Cheryl B. Aspy, PhD, Family and Preventive Medicine, University of Oklahoma Health Sciences Center, 900 NE 10th Street, Oklahoma City, OK 73104 (E-mail: cheryl-aspy@ouhsc.edu). 
For that same year, $68.1 \%$ of Oklahoma women over age 40 reported having a mammogram within the past 2 years compared with $72.8 \%$ nationally. This discrepancy between state and national rates widened and in 2006, Oklahoma women over age 40 who reported having a mammogram within the past 2 years was $67.7 \%$ compared with $76.5 \%$ of women nationally. ${ }^{11}$

Support for mammography screening in Oklahoma increased on May 10, 2004, when Governor Brad Henry signed a bill allocating \$2.5 million for breast cancer and cervical screenings for low-income Oklahomans. This removed a potential barrier for women of low income. Acting on a separate mandate from the Center for Medicare/Medicaid Services, the Oklahoma Foundation for Medical Quality launched a statewide campaign to raise the state's mammography rate in 2004 and provide education for Oklahoma women on the affordability of mammograms.

Reasons reported by women for not having a mammogram have included such things as uncertainty about effectiveness; confusing and contradicting recommendations (eg, every year versus every other year and age 50 and older vs age 40 and older); lack of financial incentives ${ }^{12,13}$; lack of time $^{14}$; and, perhaps most importantly, the lack of a systematic approach to screening within primary care office settings. ${ }^{15}$

Strategies to improve mammography rates have been numerous but have generally included single strategies such as physician education, practice audit and feedback, reminders, and flow sheets, ${ }^{16-18}$ and results have been mixed. Although integrated systematic approaches have been tested and have shown improvement, ${ }^{19,20}$ interventions are more likely to approach the screening problem by focusing only on physician behavior consistent with the following outcomes described by Ruffin et $\mathrm{al}^{21}$ : "... investigators are beating on a black box (physician behavior) with a variety of tools to modify the delivery of preventive services. The result is only marginal change or no change. Before we can intervene successfully in physician behavior, we need a far more basic understanding of physicians' practice behaviors."

One methodology showing promise in affecting physician performance is the "best practices research" method developed by Mold and Gregory. ${ }^{22}$ In this model, exemplars for the steps comprising a particular behavior under consideration are identi- fied and confirmed through practice audits. Exemplar approaches to individual steps are then assembled into a unified strategy, evaluated, and disseminated. Results using this approach have been encouraging. By tapping into the wisdom of clinicians who have "solved" parts of the problem and combining their methods, an integrated, effective approach can usually be found. ${ }^{22-24}$

The purpose of this project was to apply the best practices research methodology, in combination with a multicomponent implementation intervention (audit with feedback and benchmarking, academic detailing, and practice facilitation), to the problem of breast cancer screening within community practices that are members of a practice-based research network, with the goal of improving mammography rates.

\section{Methodology}

During a 15 -month period, we first used the best practices research methodology ${ }^{22}$ and then a multicomponent implementation intervention for breast cancer screening within the Oklahoma Physicians Resources/Research Network. Exemplars (those having mammography rates exceeding $80 \%$ of eligible patients) were identified using audit data from 48 Oklahoma Physicians Resources/Research Network clinicians from a concurrent unrelated project directed at colorectal cancer screening. An investigator (JWM) identified and queried 5 of these physician exemplars around the state and characterized their methods, identifying both general principles and specific techniques (see Table 1).

Once a set of principles and techniques was identified from interviews with exemplars and a literature review, 16 physicians (from 16 different practices) were solicited for participation in a randomized, controlled trial. Most practitioners were in solo practice (10 of 16). The others were in academic practice or in a group practice. In the intervention sites (4 solo, 2 academic, 2 group) the practice enhancement assistants (PEAs) worked with the enrolled practitioner and his/her assigned nurse to make selected changes that the practitioner felt would improve his/her ability to screen and refer women for mammograms. The clinicians in academic practice had lower volumes than the other clinicians because of fewer clinic days. There was no overlap between intervention and usual care practices because there were 16 clinicians from 16 different practices. 
Table 1. Methods Used By Primary Care Clinician Exemplars to Achieve High Rates of Mammography Screening in Their Patients

1. Make a commitment to provide prevention services, both personally and as a practice, focusing on the most important preventive services and making sure that all eligible patients are offered those services. Think about preventive services at every visit with every patient. Suggestions for critical adult preventive services include:

a. Colorectal cancer screening for all ages 50 and older;

b. Mammography for women beginning at age 40;

c. Cervical cancer screening for women ages 18 to 65 ;

d. Influenza vaccination for all ages 50 and older and anyone else who wants it;

e. One-time pneumococcal vaccination for all ages 50 and older.

2. Use a clinician/nurse reminder system of some type such as:

a. Preventive services flow sheet;

b. Special mammography stickers for women older than 40 ;

c. Preventive services reminder card that nurses complete.

3. Make the mammography appointment for the patient. (Don't ask the patient to do it.) Caveats include:

a. Ask the patient what day and time would be best (before they leave the office) so that the appointment made by your office will be convenient for them;

b. Discuss potential barriers with patients who have missed or delayed their mammograms and ask them what it would take to get them in for their mammography.

4. Use only 1 mammography center for almost all of your patients. Select the referral center based on the following:

a. Appointments should generally be available within 2 weeks;

b. Mammography center should always send a report to the patient and to you;

c. Mammography center should let you know when patients miss their scheduled appointment;

d. Mammography center should send a reminder to the patient every year (or as indicated);

e. Mammography center should do further testing without bothering you for additional orders.

5. Schedule well adult examinations on a regular basis to catch up on any preventive services that have been missed.

Physicians were randomly assigned to the intervention and usual care groups using an internet randomizer. ${ }^{25}$ The 8 physicians assigned to the intervention group received (1) audit results and a comparison with the network benchmark (benchmark data were obtained through chart audits from another project); (2) academic detailing of exemplar principles and information from the medical literature; (3) services of a practice facilitator for 9 months; and (4) information technology support if requested. Practices were free to choose (or not) from the identified exemplar strategies or to modify them as necessary to fit the practice constraints of their individual settings. The PEAs were trained in the exemplar methods and were skilled in quality improvement techniques. The "Plan, Do, Study, Act" rapid cycle quality improvement process was used to implement incremental changes and make adjustments as required. ${ }^{26}$ The PEAs spent at least 2 days per month at each practice and helped the practitioners design their interventions and facilitate the "Plan, Do, Study, Act" process. The role of the PEA was to provide information and feedback to guide the practice redesign activities. The remaining 8 practices comprised the usual care group and received no feedback or practice change facilitation.

\section{Data Collection}

A research assistant audited all practices at baseline and again after the 9-month intervention to determine the rates of mammography (defined as documentation of a mammogram within the past 2 years) before and after the intervention period. Data items for the chart audit included patient demographic characteristics, such as age, race/ethnicity, insurance type, education, marital status, number of visits in the past 12 months, whether or not a mammogram had been recommended, and whether mammography screening (binary; 1 = yes, $0=$ no) had occurred. When documentation showed that a mammogram had been recommended within the time period of interest it was noted on the data form. However, these patients remained in the denominator. Patients for whom documentation indicated that they had refused a mammogram were removed from the denominator.

Eligible patients were women 50 years of age or older who had at least one visit to the practice in the 12 months before the study implementation and who did not have a diagnosis of breast cancer. A target sample size was 100 randomly selected charts per physician for each data collection period (or as many as were eligible in the case of physicians who did not practice full-time). For the audit after intervention, women who were 50 years of age or older who had seen the clinician during the last 6 months of the intervention period (or in the last 6 months of the 9-month period after the pre-audit for the usual care group) and who did not have a diagnosis of breast cancer were included. Lists of eligible patients were generated from billing records or electronic medical record systems and 
Table 2. Methods Used by Intervention Practices to Improve Mammography Screening

\begin{tabular}{|c|c|c|c|c|c|c|}
\hline Clinician & $\begin{array}{c}\text { Rate } \\
\text { Before/After } \\
\text { Intervention } \\
\quad(\%)\end{array}$ & Method 1 & Method 2 & Method 3 & Method 4 & Method 5 \\
\hline A & $28 / 71$ & $\begin{array}{l}\text { Very committed } \\
\text { to prevention }\end{array}$ & $\begin{array}{l}\text { Nurses check chart at } \\
\text { each visit for all } \\
\text { prevention services } \\
\text { needed }\end{array}$ & $\begin{array}{l}\text { Appointment was } \\
\text { made at check- } \\
\text { out }\end{array}$ & $\begin{array}{l}\text { Appointments were } \\
\text { tracked and } \\
\text { followed up if } \\
\text { not kept }\end{array}$ & \\
\hline B & $48 / 75$ & $\begin{array}{l}\text { Very committed } \\
\text { to prevention }\end{array}$ & $\begin{array}{l}\text { Nurses checked } \\
\text { mammogram } \\
\text { eligibility at each } \\
\text { visit }\end{array}$ & $\begin{array}{l}\text { Referral was } \\
\text { made at check- } \\
\text { out }\end{array}$ & $\begin{array}{l}\text { Appointments were } \\
\text { tracked and } \\
\text { followed up if } \\
\text { not kept }\end{array}$ & \\
\hline C & $35 / 56$ & $\begin{array}{l}\text { Very committed } \\
\text { to prevention }\end{array}$ & $\begin{array}{l}\text { Nurses checked } \\
\text { mammogram } \\
\text { eligibility at each } \\
\text { visit }\end{array}$ & $\begin{array}{l}\text { Appointment was } \\
\text { made at check- } \\
\text { out }\end{array}$ & $\begin{array}{l}\text { Used one referral } \\
\text { center }\end{array}$ & \\
\hline $\mathrm{D}$ & $35 / 52$ & $\begin{array}{l}\text { Very committed } \\
\text { to prevention }\end{array}$ & $\begin{array}{l}\text { Nurses checked } \\
\text { mammogram } \\
\text { eligibility at each } \\
\text { visit }\end{array}$ & $\begin{array}{l}\text { Referral was } \\
\text { made at check- } \\
\text { out }\end{array}$ & & $\begin{array}{l}\text { Women eligible for } \\
\text { a mammogram } \\
\text { were contacted } \\
\text { for an } \\
\text { appointment }\end{array}$ \\
\hline E & $62 / 70$ & $\begin{array}{l}\text { Very committed } \\
\text { to prevention }\end{array}$ & $\begin{array}{l}\text { Nurses asked eligible } \\
\text { women about } \\
\text { mammography }\end{array}$ & $\begin{array}{l}\text { Referral was } \\
\text { made at check- } \\
\text { out }\end{array}$ & & \\
\hline $\mathrm{F}$ & $25 / 28$ & $\begin{array}{l}\text { Prevention was } \\
\text { not a priority }\end{array}$ & $\begin{array}{l}\text { Nurses asked eligible } \\
\text { women about } \\
\text { mammography }\end{array}$ & $\begin{array}{l}\text { Referral was } \\
\text { made at check- } \\
\text { out }\end{array}$ & & \\
\hline G & $56 / 56$ & $\begin{array}{l}\text { Committed to } \\
\text { prevention }\end{array}$ & $\begin{array}{l}\text { Nurses checked } \\
\text { mammogram } \\
\text { eligibility at each } \\
\text { visit }\end{array}$ & $\begin{array}{l}\text { Referral was } \\
\text { made at check- } \\
\text { out }\end{array}$ & & \\
\hline $\mathrm{H}$ & $21 / 21$ & $\begin{array}{l}\text { Prevention was } \\
\text { not a priority }\end{array}$ & & & $\begin{array}{l}\text { Used one center } \\
\text { but expected } \\
\text { patients to self- } \\
\text { refer }\end{array}$ & \\
\hline
\end{tabular}

then systematically sampled to achieve the desired number of 100 charts. If review of the chart revealed that this patient belonged to another clinician, it was skipped and the next chart on the list was substituted. All eligible charts were abstracted if the available number was less than 100 .

At the conclusion of the intervention, the PEAs summarized the methods used to improve mammography screening by each practice. In addition, the PEAs were asked to rate the practices' commitments to changing their office systems to improve delivery of preventive services. This information was used to provide more detail regarding the interventions that were implemented. Table 2 summarizes the exemplar methods used by each intervention practice.

\section{Data Analysis}

Descriptive statistics were calculated for both the pre and post chart audit data. Comparisons were made between groups for the baseline data to determine the degree to which the randomization process resulted in groups that were equivalent on the demographic characteristics. Given that the randomization was at the clinician level, comparisons of mammography rates were made at that level using $t$ tests on the calculated difference scores between percentage rates before and after the intervention. Because of the clustering of patients within clinician practices, we also conducted a Rao$\operatorname{Scott}^{27} \chi^{2}$ test, which produces an adjusted $\chi^{2}$ with 1 degree of freedom that accounts for the design effect caused by clustering, as an additional confirmation. We also calculated the interclass correlation coefficient. Availability of data for race/ethnicity, marital status, and education varied widely by provider resulting in some missing data $(68 \%$ of usual care group, $55 \%$ of the intervention group for race/ethnicity; $40 \%$ of the usual care group and $25 \%$ of the intervention group for marital status) 
Table 3. Comparison of Usual Care and Intervention Practices' Demographic Characteristics and Outcomes Before and After Intervention

\begin{tabular}{|c|c|c|c|c|c|}
\hline & \multicolumn{2}{|c|}{ Usual Care Practices $(\mathrm{n}=8)^{*}$} & \multicolumn{2}{|c|}{ Intervention Practices $(\mathrm{n}=8)^{\dagger}$} & \multirow[b]{2}{*}{$P$} \\
\hline & Before & After & Before & After & \\
\hline Patient age ${ }^{\ddagger}$ & $\begin{array}{c}\overline{\mathrm{x}}= \\
66.3 ; \mathrm{s}=3.8\end{array}$ & $\begin{array}{c}\overline{\mathrm{x}}= \\
67.2 ; \mathrm{s}=3.1\end{array}$ & $\begin{aligned} \overline{\mathrm{x}} & = \\
66.9 ; \mathrm{s} & =3.26\end{aligned}$ & $\begin{array}{c}\bar{x}= \\
65.6 ; s=2.5\end{array}$ & $>.05$ \\
\hline \multicolumn{6}{|l|}{ Insurance status (\%) } \\
\hline Private & 36 & 34 & 37 & 39 & $>.05$ \\
\hline All other & 64 & 66 & 63 & 61 & \\
\hline Current mammogram $(\%)^{\ddagger}$ & 40 & 35 & 40 & 52 & .015 \\
\hline
\end{tabular}

*Total patients of usual care group before interevention, 688; after intervention, 576.

${ }^{\dagger}$ Total patients of intervention group, before intervention, 678; after intervention, 639.

${ }^{\ddagger} t$ test of change scores.

such that reasonable comparisons could not be made. Therefore, these items were not included in the analyses. There were 28 missing values for insurance codes, and 70 "other" insurance types that included "none" or "unknown type" or "Indian Health Service." When comparing Medicaid and Medicare patients by intervention or usual care groups, there were 349 and 358 patients, respectively, in each group. For the analysis after the audit, insurance status was not a factor in mammography rates.

\section{Protection of Human Subjects}

The study was submitted to the University of Oklahoma Health Sciences Center Institutional Review Board and approved. All patient data were de-identified and all practices within the network had current HIPAA compliant Business Associate agreements with the University of Oklahoma Health Sciences Center that permitted research assistants to view their patient records. Participating physicians signed statements of informed consent.

\section{Results}

Table 3 contains the results of the comparison of the demographic before and after intervention and outcome variables by group. There was no difference in mean age or percentage of patients who were insured privately or by other means at either data collection period. Mammography rates also did not differ at baseline. Groups, however, did differ in the change rates for mammograms offered at the study's conclusion $(P=.043)$. Thirty-six percent of eligible women in the usual care group were offered a mammogram and $35 \%$ of those eligible had documentation that a mammogram had been performed. Fifty-four percent of eligible patients in the intervention group were offered a mammogram and $52 \%$ of those eligible had documentation that the mammogram had been completed. The percent of patients with current mammograms at baseline was identical for both groups (40\%). The $t$ test comparing mean change scores resulted in $t=2.78,14$ degrees of freedom, and $P=.015$, suggesting that the intervention group increased their mammography rates more than the usual care group.

Differences between the intervention and usual care groups using the Rao-Scott $\chi^{2}$ analysis to account for clustering also revealed a significant difference between the 2 groups $\left(\mathrm{x}_{\mathrm{RS}}{ }^{2}=17.49\right.$; degree of freedom $=1 ; P<.0001)$. The intraclass correlation coefficient was .114 based on 8 clusters per group with an average size of 75.8. Only 2 of the usual care practices showed an improvement, whereas 3 had rates that dropped across the study period. Mammography documentation for the intervention group ranged from a low of $21 \%$ to a high of $75 \%$; however, 6 of the 8 practices improved their mammography rates, 2 remained the same, and none declined.

In all the practices that improved their rates, the physician was highly motivated (estimated by the PEA based on leadership and involvement in the intervention) to improve, and a system for screening and referral was put into place. That did not mean that the strategy required physician action. Most practices used strategies that empowered the medical assistant to check charts at the time a patient presented to the clinic and determine 
whether the patient was eligible for a mammogram, and if so to schedule it. One practice generated a list of women who did not have evidence of a current mammogram in the chart and sent each one a reminder that it was time to schedule their mammogram; this resulted in a $49 \%$ increase in their mammography rate. Another practice with a high rate of improvement used an information technology strategy that involved tracking all referrals and providing that information to the physician so that follow-up could be initiated when a referral appointment was not kept. This strategy resulted in a $56 \%$ increase.

\section{Discussion}

The purpose of this randomized controlled trial was to determine the impact of a multicomponent intervention on mammography rates, including a practice facilitator and "best practice" methods. The results suggest that this intervention can improve mammography rates in a range of practice settings. Given the low mammography rates in the state of Oklahoma, having proven strategies that increase the number of women who choose mammography screening could potentially reduce the burden of breast cancer within the state through early detection, when treatment is more likely to be efficacious. These findings are consistent with other studies that have tested multicomponent interventions that included modified academic detailing, patient education, physician reminders, audit and feedback, prompt and reminder systems; ${ }^{28}$ physician education, and a practice facilitator to help redesign office routines including flow sheets; physician education, provider prompts, patient reminders, printed patient education materials, and transportations assistance..$^{20,29}$

It should be noted that the overall current mammography rates in both the intervention and usual care practices were lower than the reported overall state rate, which is based on telephone interviews with patients. One likely explanation is that women who receive gynecological care from a sub-specialist may also receive referrals from that specialist for mammography and the reports of results are returned to the referring physician rather than the family physician. Lack of documentation of this in the chart (even though possibly known to the physician) would be reflected by no offer of a referral and no current mammogram noted. Lack of docu- mentation of referrals and patient refusals could also have contributed. It is likely that some patients selected for the chart audits were not continuity patients, in that they could qualify for the audit by age, sex, and having had only one visit during the relevant time period. The likelihood of a mammography referral in the case of a first visit prompted by an acute problem would be low. It is also possible that the time limit (eg, a qualifying visit could occur within days of the audit) precluded an opportunity for some patients to schedule and receive a mammogram.

Despite having access to the multicomponent translational intervention, 2 of the intervention practices did not improve their mammography rates. When practice characteristics including years in practice, age, type of practice, and patient characteristics (including age and insurance type) were compared, no significant differences were found between those who improved and those who did not. For one of the practices that did not change, the physician attributed the low rate of mammograms to the lack of initiative by the patients and felt that it was their responsibility to self-refer for mammography. Consistent with that attitude, only $21 \%$ of eligible patients in that practice were offered a mammogram. The other practice that did not improve, although an aggressive method was implemented, required the nurse to review each patient chart for current mammogram status and to signal the physician if a mammogram were needed. No change was observed in the overall rate at this practice, which was just under $60 \%$. They also had an adherence to recommendation rate around $98 \%$ and the age of the patients did not differ from the overall mean, so it is not clear why the rate did not improve.

These practices were typical of many small practices where the office staffing consists of a receptionist, billing clerk, nursing or medical assistant, and a clinician. Of the 4 practices that improved the most (17 to 43 percentage points), 2 were in academic practices, one was in a group practice, and one was in solo practice. Given a desire to increase screening and referral for mammography, our study suggests that rates can be improved by selecting a process to identify those patients who need a mammogram and making a referral (or appointment for the mammogram) at that time. The consistency among successful improvers was the officewide commitment to and participation in the 
process, once again reinforcing the power of a goal in outcome achievement.

The study is limited by the small number of practices and the possibility that those selected to participate may not be representative of other practices in the research network. In addition, given the awareness of the intervention sites that their performance would be observed by the PEA and analyzed, the Hawthorne effect may have contributed to the outcome. It is also possible that having only one person interview the exemplars resulted in the exclusion of a strategy from the best practices suggestions that might have been even more effective.

Despite these limitations, this study found that using a multicomponent translational intervention consisting of academic detailing, audit feedback with benchmarking, and practice facilitation resulted in significant improvement in mammography rates. Although baseline motivation to improve is a factor, it should be noted that each of the intervention components was designed to motivate the practices toward incremental system changes that would ultimately improve their rates of performance.

\section{References}

1. US Preventive Services Task Force. Guide to clinical preventive services. Washington, DC: Office of Disease Prevention and Health Promotion; 2002.

2. Alexander FE, Anderson TJ, Brown HK, et al. 14 years of follow-up from the Edinburgh randomised trial of breast-cancer screening. Lancet. 1999;353: 1903-8.

3. Andersson I, Janzon L. Reduced breast cancer mortality in women under age 50: updated results from the Malmo Mammographic Screening Program. J Natl Cancer Inst Monogr 1997;(22):63-7.

4. Bjurstam N, Bjorneld L, Duffy SW, et al. The Gothenburg breast screening trial: first results on mortality, incidence, and mode of detection for women ages 39-49 years at randomization. Cancer 1997; 80:2091-9.

5. Frisell J, Lidbrink E, Hellstrom L, Rutqvist LE. Follow-up after 11 years-update of mortality results in the Stockholm mammographic screening trial. Breast Cancer Res Treat. 1997;45:263-70.

6. Shapiro S. Periodic screening for breast cancer: the HIP Randomized Controlled Trial. Health Insurance Plan. J Natl Cancer Inst Monogr 1997;(22):2730.

7. Tabar L, Vitak B, Chen HH, et al. The Swedish Two-County Trial twenty years later. Updated mortality results and new insights from long-term follow-up. Radiol Clin North Am 2000;38:625-51.
8. Humphrey LL, Helfand M, Chan BK, Woolf SH. Breast cancer screening: a summary of the evidence for the US Preventive Services Task Force. Ann Int Med 2002;137(5 Pt 1):347-60.

9. Berry DA, Cronin KA, Plevritis SK, et al. Effect of screening and adjuvant therapy on mortality from breast cancer. N Engl J Med 2005;353:1784-92.

10. Oklahoma State Department of Health. Female breast cancer in Oklahoma. Chronic Disease Service 2000;1:1-4.

11. Centers for Disease Control and Prevention. Behavioral risk factor surveillance system survey data. Atlanta (GA): US Department of Health and Human Services, Centers for Disease Control and Prevention; 2004.

12. Belcher DW, Berg AO, Inui TS. Practical approaches to providing better preventive care: are physicians a problem or a solution? Am J Prev Med 1988;4(4 Suppl):27-48; discussion, 49-52.

13. Frame PS. Health maintenance in clinical practice: strategies and barriers. Am Fam Physician 1992;45: 1192-200.

14. Kottke TE, Brekke ML, Solberg LI. Making "time" for preventive services. Mayo Clin Proc 1993;68: $785-91$.

15. Leininger LS, Finn L, Dickey L, et al. An office system for organizing preventive services: a report by the American Cancer Society Advisory Group on Preventive Health Care Reminder Systems. Arch Fam Med 1996;5:108-15.

16. Hahn D, Berger M. Implementation of a systematic health maintenance protocol in a private practice. $\mathrm{J}$ Fam Pract 1990;31:492-504.

17. Pommerenke F. Implementing preventive services: practical strategies for primary care physicians. Cancer Prev 1992;3:1-13.

18. McPhee S, Bird J, Fordham D, Rodnick J, Osborn E. Promoting cancer prevention activities by primary care physicians. JAMA 1991;266:538-44.

19. Gemson D, Ashford A, Dickey L, et al. Putting prevention into practice: impact of a multifaceted physician education program on preventive services in the inner city. Arch Intern Med 1995;155:2210-6.

20. Dietrich A, O'Connor G, Keller A, Carney P, Levy D, Whaley F. Cancer: improving early detection and prevention: a community practice randomized trial. BMJ 1992;304:687-91.

21. Ruffin MT, Gorenflo DW, Woodman B. Predictors of screening for breast, cervical, colorectal, and prostatic cancer among community-based primary care practices. J Am Board Fam Pract 2000;13:1-10.

22. Mold JW, Gregory M. Best practices research. Fam Med 2003;35:131-4.

23. Cotton A, Aspy CB, Mold J, Stein H. Clinical decision-making in blood pressure management of patients with diabetes mellitus: an Oklahoma Physicians Resource/Research Network (OKPRN) Study. J Am Board Fam Med 2006;19:232-9. 
24. Ferrell CW, Aspy CB, Mold JW. Management of prescription refills in primary care: an Oklahoma physicians Resources/Research Network (OKPRN) Study. J Am Board Fam Med 2006;19:31-8.

25. Urbaniak GC, Plous S. Research Randomizer. c1997-2008. Available from: http://www.randomizer. org/form.htm. Accessed 30 April 2008.

26. Deming WE. The new economics for industry, government, education, 2nd ed. Cambridge (MA): The MIT Press; 2000.
27. Rao JN, Scott AJ. A simple method for the analysis of clustered binary data. Biometrics. 1992;48:57785.

28. Preston JA, Scinto JD, Grady JN, Schulz AF, Petrillo MK. The effect of a multifaceted physician office-based intervention on older women's mammography use. J Am Geriatr Soc 2000;48:1-7.

29. Taylor V, Thompson B, Lessler D, Yasui Y, Montano D, Johnson KM. Strategies that improve mammography screening rates. JCOM 1999;6:21. 